\title{
Validation and quantification of major biomarkers in 'Mahasudarshan Churna'- an ayurvedic polyherbal formulation through high-performance thin-layer chromatography
}

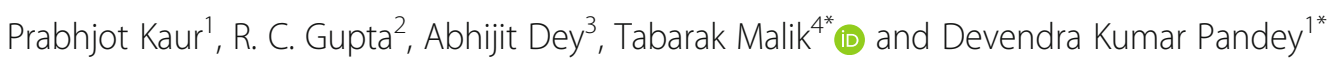

\begin{abstract}
Background: Mahasudarshan Churna (MC) is a polyherbal Ayurvedic medicine that is employed in fever (especially chronic type), cold and malaria, improvement of digestion and appetite, removes toxins from the blood, boosts immunity and protects against common bacterial infections.

Methods: Validation and quantification of oleanolic acid (OA), ursolic acid (UA), mangiferin (M), gallic acid (GA), quercetin $(\mathrm{Q})$ and curcumin $(\mathrm{C})$ in commercial MC formulations by HPTLC method. Mobile phase, hexane: ethyl acetate: acetone (16.4: 3.6: 0.2, v/V) was used for the separation of $O A$ and $U A$; ethyl acetate: glacial acetic acid: formic acid: water (20: 2.2: 2.2: $5.2 \mathrm{v} / \mathrm{V}$ ) for the development of $\mathrm{M}$; and toluene: ethyl acetate: formic acid (13.5: 9: 0.6 $\mathrm{v} / \mathrm{V}$ ) for the separation of $\mathrm{GA}, \mathrm{Q}$ and $\mathrm{C}$ in crude sample extracts. Visualization and scanning were performed at $\lambda=$ $530 \mathrm{~nm}$ for OA and UA, at $\lambda=254 \mathrm{~nm}$ for $M$ and at $\lambda=366 \mathrm{~nm}$ for GA, Q and C. In addition, HPLC-PDA analysis was used to confirm the HPTLC results.
\end{abstract}

Results: Major bio-active compounds in MC formulations were oleanolic acid (1.54-1.78\%), mangiferin (1.38-1.52\%) and gallic acid (1.01-1.15\%); followed by ursolic acid (0.79-0.98\%), curcumin (0.45-0.67\%) and quercetin (0.22$0.34 \%)$.

\footnotetext{
*Correspondence: malikitrc@gmail.com; dkpandey1974@gmail.com; dkpandey1974@yahoo.com

${ }^{4}$ Department of Biochemistry, College of Medicine and Health Sciences, University of Gondar, Gondar, Ethiopia

'Department of Biotechnology, Lovely Faculty of Technology and Sciences, Lovely Professional University, Phagwara, Punjab 144411, India

Full list of author information is available at the end of the article
}

(c) The Author(s). 2020 Open Access This article is licensed under a Creative Commons Attribution 4.0 International License, which permits use, sharing, adaptation, distribution and reproduction in any medium or format, as long as you give appropriate credit to the original author(s) and the source, provide a link to the Creative Commons licence, and indicate if changes were made. The images or other third party material in this article are included in the article's Creative Commons licence, unless indicated otherwise in a credit line to the material. If material is not included in the article's Creative Commons licence and your intended use is not permitted by statutory regulation or exceeds the permitted use, you will need to obtain permission directly from the copyright holder. To view a copy of this licence, visit http://creativecommons.org/licenses/by/4.0/ The Creative Commons Public Domain Dedication waiver (http://creativecommons.org/publicdomain/zero/1.0/) applies to the data made available in this article, unless otherwise stated in a credit line to the data. 


\begin{abstract}
(Continued from previous page)
Conclusion: Analysis of bio-active compounds in the present study was performed using HPTLC methods and later HPTLC results were compared with HPLC. These two methods give comparable results and there was no statistically significant difference between the mean values for all extracts. Present study concluded that this HPTLC technique is low cost, fast, precise, and accurate which can be employed for the quantification of xanthonoid (M), triterpenoids (OA, UA) and phenolics (GA, Q and C) in samples/formulations. Furthermore, present HPTLC method can be conveniently employed for routine quality control analysis of all the six marker compounds in marketed Ayurvedic/herbal formulations.
\end{abstract}

Keywords: Mahasudarshan churna, Swertia chirata, HPTLC, Standardization, Polyherbal formulations

\section{Background}

Ayurveda system of medicine is beneficial to mankind, but still there is a lack of proper standardizing techniques for the assessment of their quality, quantity and efficiency. According to WHO guidelines, chromatographic techniques are reliable and effectively implemented to standardize and quantify the major biomarker compounds from single drug and polyherbal formulation. The application of medicinal plants in curing diseases is the oldest prevailing system to deal with illness. In ancient civilized countries like India, China, Egypt, Africa, South America, etc. $80 \%$ population depends upon traditional Medicine (TM) system to cure innumerable deadly diseases like cancer, AIDS, Malaria etc. A number of indigenous systems such as Siddha, Ayurveda and Unani medicines reveal the existence of around 800 medicinal plants [1]. In the twentieth century, the development of synthetic medicines has led to a decline in the use of herbal medicines. In recent years, herbal medicines have gradually gained considerable approval and fame due to the extensive research of pharmacological effects in human health care. Although much attention and research has been attempted in current years, there is still insufficient information about the phytochemical and metabolomics of herbal medicines, which has created a major challenge in standardization methods [2]. Herbal drugs or phytomedicine should follow the proper safety and efficacy principles for the well-being of mankind [3]. Hence, framework has been required for the quality control and standardization protocols of the herbal drugs.

Ayurveda formulations are of two types: prepared only from one herb and poly herbal formulations that are prepared from the combination of many herbs [4]. As defined in the literature, maximum quality control of herbal ingredients focuses on observational tests viz. macroscopic, microscopic and physicochemical studies [5]. Therefore, standardization protocols using nonconventional analytical practices are required for authentication of herbal/ poly herbal Ayurvedic formulations. At present, phytochemical screening of bioactive marker compounds becomes more effective in the authentication of herbal drugs, and thus helps to reduce adulteration [6, 7].

Mahasudarshan Churna (MC) is a polyherbal ayurvedic medicine that is extensively used in treatment of all types of fever, cold, malaria, liver and spleen diseases [8]. MC helps to improve digestion and appetite; removes toxins from the blood; boosts immunity and protects against common bacterial infections; promote perspiration and urination. MC formulation is known for antimalarial, antioxidant, antipyretic, antiviral and anti-diabetic properties [9]. MC consists of Kiratatikta (Swertia chirata) as a principal component along with other 49 Ingredients [10].

Swertia chirata Buch.-Ham. ex C. B. Clarke (Family: Gentianaceae) is a bitter medicinal plant native to temperate regions all over the world. Swertia genus is present at the high altitudes of western and eastern Himalayas in India, Nepal and Bhutan regions. This herb is also recognized as kirata Tikta, kairata (Sanskrit), Qasabuzzarirah (Arabic, Farsi), Chiravata (Urdu) and Chiretta (trade name). Whole plant of Swertia chirata is also exported from India for medicinal purpose [1]. Traditionally, whole plant of Swertia chirata has been used to treat various illnesses such as malaria, cough, cold, chronic fever, tremor fever, liver disorders, stomach disorders, asthma etc. [11]. Among all the compounds extracted from Swertia genus, important phytochemical bio-markers are xanthonoids, secoiridoids, triterpenoids $[12,13]$. Major xanthonoid compound is mangiferin that shows important pharmacological effects such as anti-oxidant, antidiabetic, antiparkinson, anti-inflammatory, chemopreventive, hypoglycemic, cardiotonic and diuretics properties [14]. Major triterpenoids are Oleanolic acid (OA) and Ursolic acid (UA) that are also considered as significant phytochemical bio-marker compounds [15].

To determine the efficacy and authenticity of herbal drugs, chromatographic based analysis have been acknowledged internationally [2]. High-performance ThinLayer Chromatography (HPTLC) has been developed as an effective technique for the recognition and quality control of some polyherbal formulations viz. 'Trikatu 
Churna'; 'Draksharishta'; 'Entoban capsules'; 'Sitopaladi churna'; 'Hingavastaka churna'; 'Avipattikara churna'; 'Sringyadi churna'; 'Talisadya churna' [16-18]. Some physicochemical parameters for the standardization of MC formulation have been investigated [10]. Development of standardization methods of this important formulation based on modern analytical technique is required. The objective of current work was the development and validation of HPTLC technique based on the major bio-markers (xanthonoid-mangiferin, triterpenoids- oleanolic acid and ursolic acid, phenolic compounds-gallic acid, quercetin and curcumin) for proper standardization of MC formulation. This is the first time reporting for the qualitative and quantitative estimation of these significant bio-active compounds in $\mathrm{MC}$ formulation.

\section{Methods}

\section{Plant materials and chemicals}

Three commercial brands of 'Mahasudarshan Churna' (MC) viz. Dabur (MC1), Baidyanath (MC2) and Zandu (MC3) were procured from store of Ludhiana, Punjab (India). The authentic standards - Mangiferin, Oleanolic acid, Ursolic acid, gallic acid, curcumin and quercetin standards were purchased from Sigma-Aldrich (USA). All chemicals and solvents used in our experimentation were of HPLC grade.

Matured plants of Swertia chirata Buch.-Ham. ex C. B. Clarke were collected in flowering stage from ChakrataDeoban region, Uttarakhand $\left(30.798624^{\circ} \mathrm{N}, 77.780368^{\circ}\right.$ E; altitude $2600 \mathrm{~m}$ ) during the month of October, 2017 from wild. Curcuma longa L. rhizome was collected from Herbal garden, Lovely Professional University, Phagwara, Punjab. Both the plants were authenticated on the basis of morphological characters by Prof. R. C Gupta, taxonomist expert. The Voucher specimens of Swertia chirata (No. 01102017) and Curcuma longa (No. 11122017) were prepared and deposited in the Department of Botany, Lovely Professional University, Phagwara, Punjab, India.

\section{HPTLC instrumentation and chromatographic condition}

HPTLC system (CAMAG) consists of $100 \mathrm{~mL}$ syringe (Hamilton, Bonaduz, Switzerland) and Linomat V automatic sample applicator (CAMAG, Muttenz, Switzerland). CAMAG glass twin trough chamber $(20$ $\mathrm{cm} \times 10 \mathrm{~cm} \times 4 \mathrm{~cm}$ ) with stainless steel lid cover, CAMAG TLC Scanner III, CAMAG win Cats 3 integration software and UV cabinet with dual wavelength UV lamp $(254 \mathrm{~nm}$ and $366 \mathrm{~nm})$ was used for the HPTLC analysis. HPTLC analyses were performed on $20 \times 10 \mathrm{~cm}$ pre-coated with silica gel 60 F254 (E-Merck) $(0.2 \mathrm{~mm}$ thickness). HPTLC experiments were conducted at $25 \pm$ $2{ }^{\circ} \mathrm{C}$ temperature and $40 \%$ relative humidity.
Qualitative and quantitative determination of mangiferin, oleanolic acid, ursolic acid, gallic acid, quercetin and curcumin by HPTLC

Extraction and preparation of test samples for HPTLC

All the MC (Mahasudarshan churna) powdered samples $(1.0 \mathrm{~g})$ were extracted with microwave assisted extraction (MAE) method in $100 \mathrm{ml}$ closed vessel units by using methanol solvent. Microwave extraction conditions were set at optimized conditions: microwave power $(450 \mathrm{~W})$, time (4 min), solid: solvent $(20 \mathrm{~mL})$.

Extracts were cooled, filtered through Whatman no. 1 filter paper and extracts were dried in rotary evaporator. Final volume of all the extracts was prepared with methanol $\left(10 \mathrm{mg} \mathrm{mL}^{-1}\right)$, mixed well and then centrifuged the tubes for $5 \mathrm{~min}$ at $7500 \mathrm{rpm}\left(4^{\circ} \mathrm{C}\right)$ to get clear extracts. All the prepared extracts were kept in refrigerator at $4{ }^{\circ} \mathrm{C}$ for further phytochemical analysis. All the extraction procedures were completed in triplicates and their respective mean values were considered for yield.

\section{Preparation of standard solution}

The standards i.e. mangiferin, oleanolic acid, ursolic acid, gallic acid, curcumin and quercetin (10 mg each) were weighed accurately and standard solutions were prepared by adding $10 \mathrm{~mL}$ of methanol to produce $1 \mathrm{mg}$ $\mathrm{mL}^{-1}$ concentration of standards.

HPTLC method development and validation for mangiferin, oleanolic acid, ursolic acid, gallic acid, quercetin and curcumin

The HPTLC plates were cleaned by predevelopment by using methanol and dried in oven at $105^{\circ} \mathrm{C}$ before loading the test samples. Standards and samples were applied by means of applicator equipped with a Hamilton syringe of $100 \mu \mathrm{L}$ capacity on HPTLC plates with the following settings: bands size, $5 \mathrm{~mm}$; specific distance kept between the two bands, $14 \mathrm{~mm}$; application rate, 150 $\mathrm{nLs}^{-1}$; the distance from bottom of the plate $2 \mathrm{~cm}$. Standard solutions of OA, UA, M, GA, Q and C were applied in triplicate on HPTLC plates using an automatic sample spotter (Linomat V) to get final concentration. The peak area was recorded and calibration curves were obtained by plotting peak area versus concentrations of the standards.

$5 \mu \mathrm{L}$ of each MC sample was loaded in triplicates on HPTLC plate. Optimized mobile phase for mangiferin $(\mathrm{M})$, triterpenoids (OA, UA) and phenolics $(\mathrm{GA}, \mathrm{Q}, \mathrm{C})$ were ethyl acetate: glacial acetic acid: formic acid: water (20: 2.2: 2.2: $5.2 \mathrm{v} / \mathrm{v}), \mathrm{n}$-hexane: ethyl acetate: acetone (16.4: 3.6: $0.2 \mathrm{v} / \mathrm{v})$ and toluene: ethyl acetate: formic acid (13.5: 9: $0.6 \mathrm{v} / \mathrm{v})$ respectively and plate were developed in twin-tough chamber (CAMAG) upto $7.5 \mathrm{~cm}$. For OA and UA, HPTLC plate was pre-derivatized with $1 \%$ iodine solution in chloroform upto a distance of $3.5 \mathrm{~cm}$, 
and was placed in dark for $10-15 \mathrm{~min}$. The plates were dried with dryer to remove the excess of iodine after completion of the reaction. After development, HPTLC plate was post-derivatized with $5 \%(\mathrm{v} / \mathrm{v})$ ethanolic sulphuric acid solution and after drying, heated in an oven at $110^{\circ} \mathrm{C}$ for $2 \mathrm{~min}$ [15]. Quantitative evaluation of the plate was performed by keeping slit dimensions $4 \times$ $0.33 \mathrm{~mm}$, scanning speed, $20 \mathrm{~mm} \mathrm{~s}^{-1}$ at a wavelength of $\lambda=254 \mathrm{~nm}$ for xanthanoid, $\lambda=520 \mathrm{~nm}$ for triterpenoid and $\lambda=254 \mathrm{~nm}$ for phenolics.

\section{HPLC analysis}

Analysis was performed with HPLC-PDA detector System (Waters) equipped with an auto sampler, a dual low-pressure gradient system, C-18 column. HPLC conditions were optimized with isocratic elution and $1 \mathrm{~mL} /$ min flow rate. Working solutions of the samples were prepared at $100 \mathrm{ppm}$ concentrations, and injection volume was set at $10 \mu \mathrm{L}$. Chromatographic separation was conducted at room temperature using Sunfire C-18 column $(4.6 \mathrm{~mm} \times 250 \mathrm{~mm} ; 5 \mu \mathrm{m}$ particle size). Before injection, column was equilibrated for $10 \mathrm{~min}$.

For estimation of mangiferin, acetonitrile (A) was used as eluent $\mathrm{A}$ and water with $0.1 \%$ formic acid as eluent $\mathrm{B}$ using the following gradient program: $20-46 \%$ A $(0-1.0$ $\mathrm{min}) ; 46-46 \% \mathrm{~A}(1.0-2.5 \mathrm{~min}) ; 46-20 \% \mathrm{~A}(2.5-4.0 \mathrm{~min})$ and $20-20 \%$ A (4.0-9.0 min). On the other hand, mobile phase for simultaneous determination of gallic acid and quercetin was consisted of water (A) and methanol (B). $\mathrm{UV} / \mathrm{Vis}$ absorption spectra were recorded in the range of 200-600 nm. Identification of these compounds by chromatography was achieved by interpolation of multi-level standard curves made with authentic standards and retention time comparison. Quantitative analysis in UV/ Vis based detection systems was accomplished using linear calibration curves generated with authentic standards of mangiferin, gallic acid and quercetin. Stock solutions of authentic standards $(1 \mathrm{mg} / \mathrm{mL})$ were prepared in pure methanol and made up to seven dilutions using methanol.

\section{Method validation}

For the validation of the analytical method development, ICH guidelines were followed for precision, repeatability and accuracy.

\section{Instrument precision}

Instrument precision was evaluated by analyzing the same spot of OA (600 ng/spot), UA (600 ng/spot), mangiferin (400 ng/spot), GA (600 ng/spot), Quercetin (400/ spot) and curcumin (300 ng/spot) and expressed as relative standard deviation $(\% R S D)$.

\section{Precision}

Precision was studied by analyzing six bands $(n=6)$ of both sample and standard solutions per plate on three plates (intra-day precision) and on three consecutive days (inter-days precision) at three different quantities (400, 600, $800 \mathrm{ng} / \mathrm{spot}$ for OA, UA and GA; 300, 400, $500 \mathrm{ng} / \mathrm{spot}$ for mangiferin and Quercetin; 200, 300, 400 $\mathrm{ng} / \mathrm{spot}$ for curcumin).

The intra-day (repeatability) and inter-day (intermediate precision) precisions were performed by these three different concentration levels of standard and sample solutions and all results were expressed as mean $\pm R S D$ (\%).

\section{Limits of detection (LOD) and quantification (LOQ)}

For the determination of LOD and LOQ, different concentrations of $\mathrm{M}, \mathrm{OA}, \mathrm{UA}, \mathrm{GA}, \mathrm{Q}$ and $\mathrm{C}$ were applied along with methanol as a blank and evaluated on the basis of signal-to-noise $(\mathrm{S} / \mathrm{N})$ ratio. The LOD was considered as 3:1 (SD/S) and LOQ as 10:1 (SD/S); S: slope of the calibration curve and SD: standard deviation of the $\mathrm{Y}$-intercept of the regression line.

\section{Accuracy and recovery studies}

The accuracy of the method was established by the measurement of the recovery of standards at three different concentration (50, 100 and 150\%) of xanthanoid (mangiferin), triterpenoids (oleanolic acid, ursolic acid) and phenolics (gallic acid, quercetin and Curcumin) using the standard addition method.

The known volume of MC solution (each taken in four different funnel), mangiferin stock solution $\left(1 \mathrm{mg} \mathrm{mL}^{-1}\right)$ equivalent to $0.0,2.0,4.0$ and $6.0 \mu \mathrm{g}$ were added individually to each of the separating funnels. Seven replicate analyses were performed on each extract and the amount of mangiferin recovered from the samples was determined for each level. The recovery analysis was repeated similarly for triterpenoids (oleanolic acid, ursolic acid) and phenolics (gallic acid, quercetin and Curcumin) with $\mathrm{MC}$ solutions.

\section{Specificity}

Peak purity of the standard and test sample was determined for specificity of the method. The spot of each standard in the sample was confirmed by the $R_{f}$ values and spectra of the separated bands with those of the standards at three different levels i.e. peak start, peak apex and peak end of the spot.

\section{Results}

\section{Development of optimum mobile phase}

In this study, quantitative estimation of specific bioactive compounds viz. M, OA, UA, GA, CA and curcumin was conducted in the commercial polyherbal formulations 

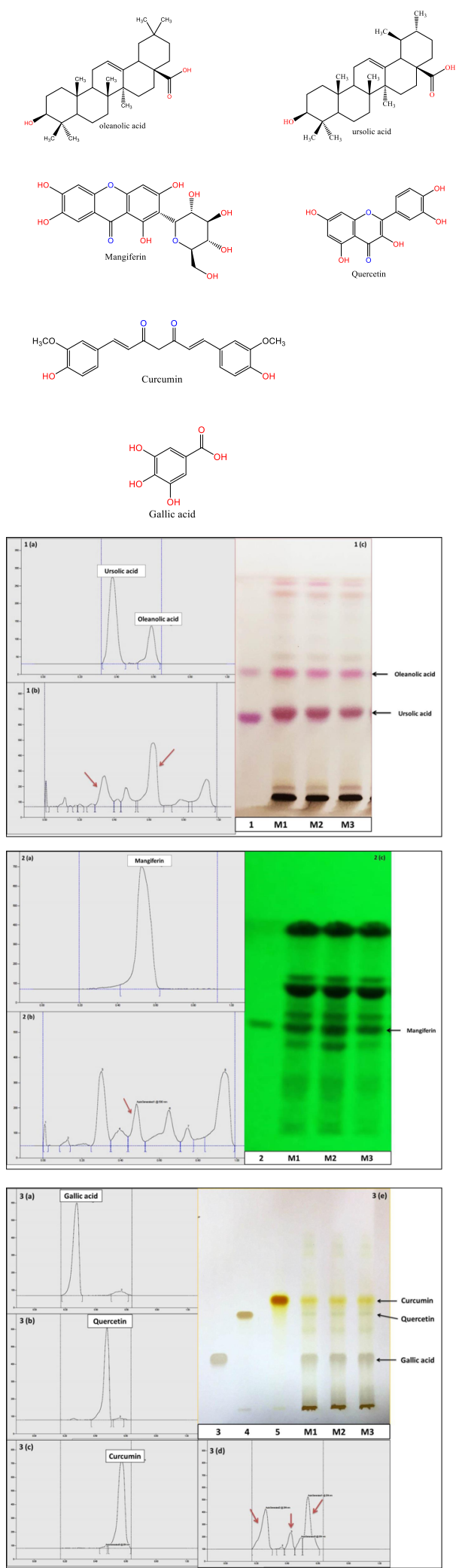

Fig. 1 Densitogram obtained from Standard- ursolic and oleanolic acid (1 a) using n-hexane: ethyl acetate: acetone (16.4: 3.6: $0.2 \mathrm{v} / \mathrm{v}$ ) mobile phase; formulation samples containing ursolic and oleanolic acid (1 b); Standard-mangiferin (2 a); formulation samples containing mangiferin (2 b) using ethyl acetate: glacial acetic acid: formic acid: water (20: 2.2: 2.2: $5.2 \mathrm{v} / \mathrm{v}$ ) mobile phase; Standard- gallic acid (3 a); Standard- quercetin (3 b); Standard-curcumin (3 c) using toluene: ethyl acetate: formic acid (13.5: 9: $0.6 \mathrm{v} / \mathrm{v}$ ) mobile phase; and formulation samples contains gallic acid, quercetin and curcumin (3 d). HPTLC fingerprinting (1c;2c; 3e) showing track $1 ; 2 ; 3-5$ : STANDARD-oleanolic and ursolic acid; mangiferin; gallic acid; quercetin and curcumin respectively where tracks M1, M2 and M3 signifying marker compounds in three different commercial formulations (MC1, MC2 and MC3)

using HPTLC technique. In order to optimize the best solvent system for good resolution and separation of chosen bioactive compounds, various trials were carried out. Well resolved spot with significant $R_{f}$ for determination of xanthonoid (M), triterpenoids (OA, UA) and phenolics (GA, Q and C) in formulations was developed. M, OA, UA, GA and $\mathrm{Q}$, the common phyto-constituents in Swertia chirata and curcumin, the major bioactive marker compound of Curcuma longa, were well represented in the chromatograms (Fig. 1 a, b, c). For optimization of method, different mobile phase compositions were employed to achieve good separation and resolution of these bioactive compounds. Of different solvent systems used for the detection of M, OA, UA, GA, $\mathrm{Q}$ and $\mathrm{C}$, the solvent system containing ethyl acetate: glacial acetic acid: formic acid: water (20: 2.2: 2.2: $5.2 \mathrm{v} / \mathrm{v} / \mathrm{v} / \mathrm{v}), \mathrm{n}$-hexane: ethyl acetate: acetone (16.4: 3.6: $0.2 \mathrm{v} / \mathrm{v}$ ) and toluene: ethyl acetate: formic acid (13.5: 9: $0.6 \mathrm{v} / \mathrm{v})$ resulted in good resolution of the xanthanoid, triterpenoids and phenolics in the presence of other compounds in the formulation. The $R_{f}$ obtained for oleanolic acid is 0.59 and ursolic acid is 0.38. The $R_{f}$ of mangiferin is 0.53 . $R_{f}$ obtained for gallic acid, quercetin and curcumin is $0.28,0.48$ and 0.56 , respectively. The $R_{f}$ value of the triterpenoids (OA, UA), xanthonoid (mangiferin), and phenolics (GA, CA and curcumin) in different solvents system with reference standard and polyherbal formulations (MC) were found comparable under $520 \mathrm{~nm}$ (Fig. 2), $254 \mathrm{~nm}$ (Fig. 3), and $366 \mathrm{~nm}$ (Fig. 4) respectively. The TLC chamber was pre-saturated with the mobile phase for $5 \mathrm{~min}$ at room temperature to get welldefined band. The three-dimensional HPTLC overlay of triterpenoids (OA, UA), xanthonoid (M), and phenolics (GA, Q and C) are shown in Figs. 2, 3 and 4.

In addition, HPLC-PDA analysis was used to confirm the HPTLC results (Additional file 1: Fig. S1 and S2). 
Calibration curves of Mangiferin, Oleanolic acid, Ursolic acid, gallic acid, quercetin and Curcumin and their analysis in formulations

Calibration curve was found to be linear at 200-800 ng/band for mangiferin, 200-3000 ng/band for triterpenoids (OA and UA), 500-2000 ng/band for gallic acid, 300-1500 ng/band for quercetin and 100-1000 ng/band for curcumin. The results are tabulated in Table 1 . The precision of xanthonoid $(\mathrm{M})$, triterpenoids (OA, UA) and phenolics (GA, Q and C) are shown in Table 2. The intra-day and inter-day precision results are found to be precise as shown in Table 2.
Quantification of bioactive compounds in commercial Mahasudarshan Churna formulations by HPTLC and HPLC HPTLC method was used for qualitative and quantitative estimation of six major bioactive compounds; viz. oleanolic acid, ursolic acid, mangiferin, gallic acid, quercetin and curcumin in all the test samples of MC. The chromatograms and HPTLC fingerprints of the all standard compounds along with crude extract of $\mathrm{MC}$ samples are presented in Fig. 1. MC formulations (MC1, MC2 and MC3) were found to contain oleanolic acid (1.54-1.78\%), mangiferin (1.38-1.52\%) and gallic acid

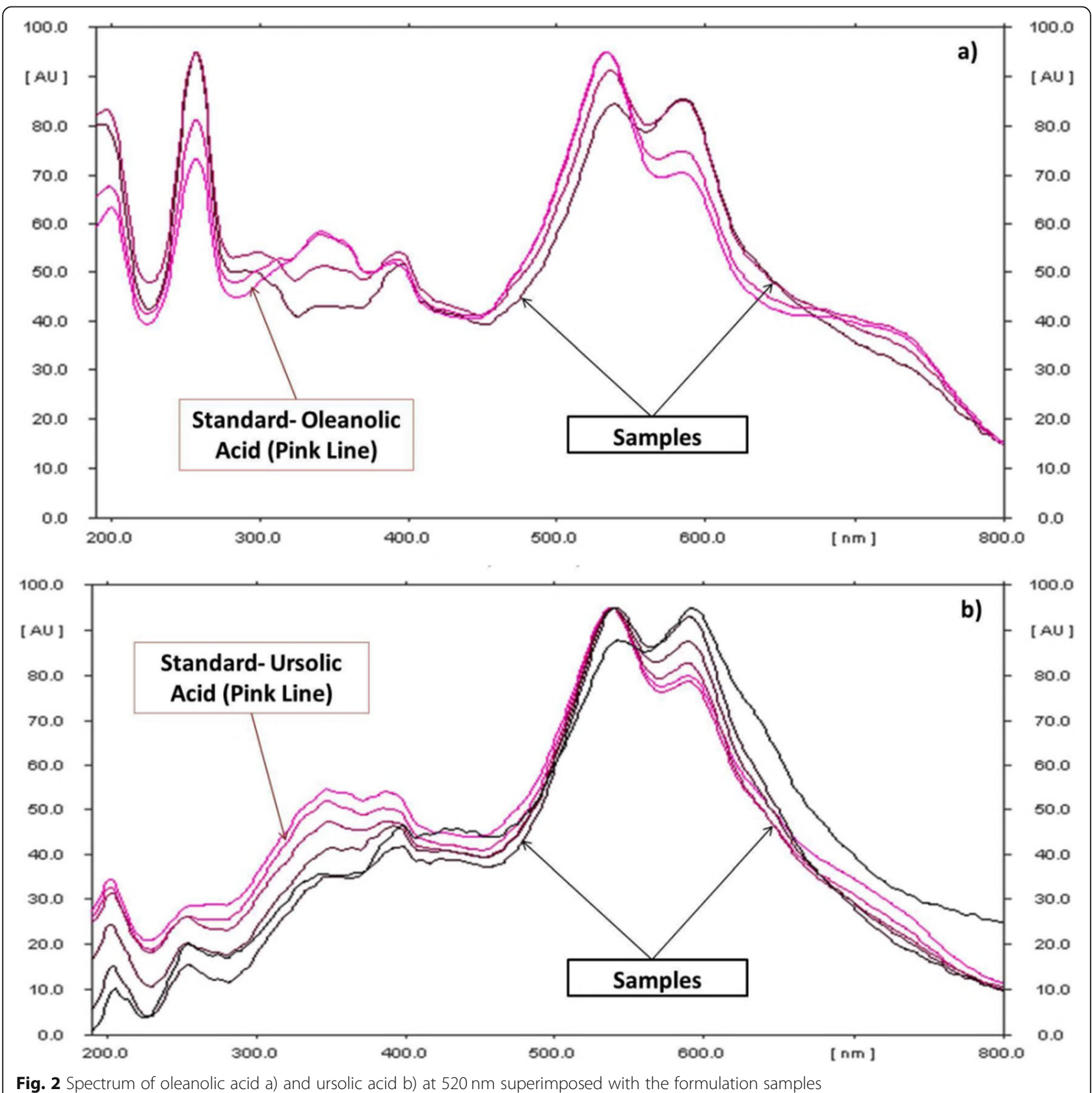




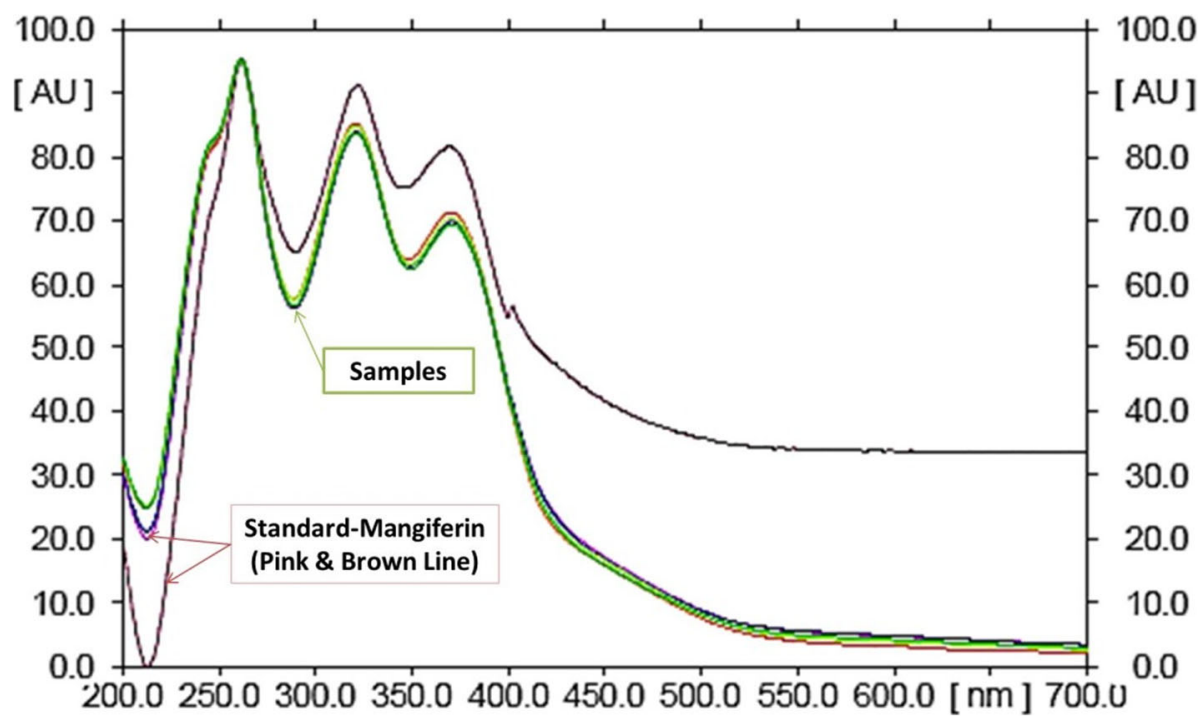

Fig. 3 Spectrum of mangiferin at $254 \mathrm{~nm}$ superimposed with the formulation samples

(1.01-1.15\%), followed by ursolic acid (0.79-0.98\%), curcumin $(0.45-0.67 \%)$ and quercetin $(0.22-0.34 \%)$ content with HPTLC analytical method.

In addition, HPLC-PDA analysis was used to confirm the HPTLC results. In present study, quantification of only three compounds; viz. mangiferin, gallic acid and quercetin was performed using HPLC method. In this method, MC formulations (MC1, MC2 and MC3) were found to contain mangiferin (1.36-1.54\%); gallic acid (1.06-1.12\%) and quercetin (0.20-0.36\%) content.

\section{Limit of detection and quantification}

The LOD and LOQ of xanthonoid (M), triterpenoids (OA, UA) and phenolics (GA, Q and C) are shown in Table 1 which indicates the adequate sensitivity of the method.

\section{Accuracy and recovery studies}

Accuracy was investigated by the application of 50, 100 and $150 \%$ of xanthonoid (M), triterpenoids (OA, UA) and phenolics (GA, Q and $\mathrm{C}$ ) in the Mahasudarshan churna formulations extract. Average recovery for xanthonoid (mangiferin), triterpenoids (oleanolic acid and ursolic acid) and phenolics (gallic acid, quercetin and curcumin) for the marketed formulation of Mahasudarshan churna are depicted in Table 2.

\section{Specificity}

The peak purity was calculated as per regression $\left(r^{2}\right)$. The values for mangiferin, OA, UA, GA, quercetin and curcumin are presented in Table 2. Chromatographic specificity was investigated by comparing the $R_{f}$ value of standard compounds and test samples and it was found to be identical. The specificity of the method is checked and no impurities or degradation products were found in samples and the peaks of standard drug solutions.

\section{Discussion}

Herbal medicines (HMs) including Chinese medicine (CM) and other folk medicines are getting more and more popular around the world nowadays, in order to improve the health condition of human beings. The use of medicinal plants as therapeutics is the oldest prevalent system to deal with illness, but still there is a lack of proper standardizing techniques for the assessment of their quality, quantity and efficiency [19]. According to WHO guiding principle, chromatographic procedures are most effective for the standardization and quantification of value-added bio-active compounds from herbal/ polyherbal formulations [3].

Mahasudarshan Churna (MC) is a polyherbal Ayurveda medicine, which is known for antimalarial, antioxidant, antipyretic, antiviral and anti-diabetic properties [8]. Swertia chirata is known as principal component of $\mathrm{MC}$; however, framework for the quality control and standardization protocols of this formulation is still unclear. Xanthonoids (mangiferin), secoiridoids (swertiamarin and amarogentin) and triterpenoids (oleanolic acid and ursolic acid) are bio-markers compounds of Swertia genus [12, 13]; therefore, this study was designed for the qualitative and quantitative analysis of major bioactive compounds in $\mathrm{MC}$.

In present study, a validated Densitometric- HPTLC (high performance thin layer chromatography) method has been developed for the determination of major biomarkers (xanthonoid-mangiferin, triterpenoids- oleanolic acid and ursolic acid, phenolic compounds-gallic acid, quercetin and curcumin) in Mahasudarshan Churna 

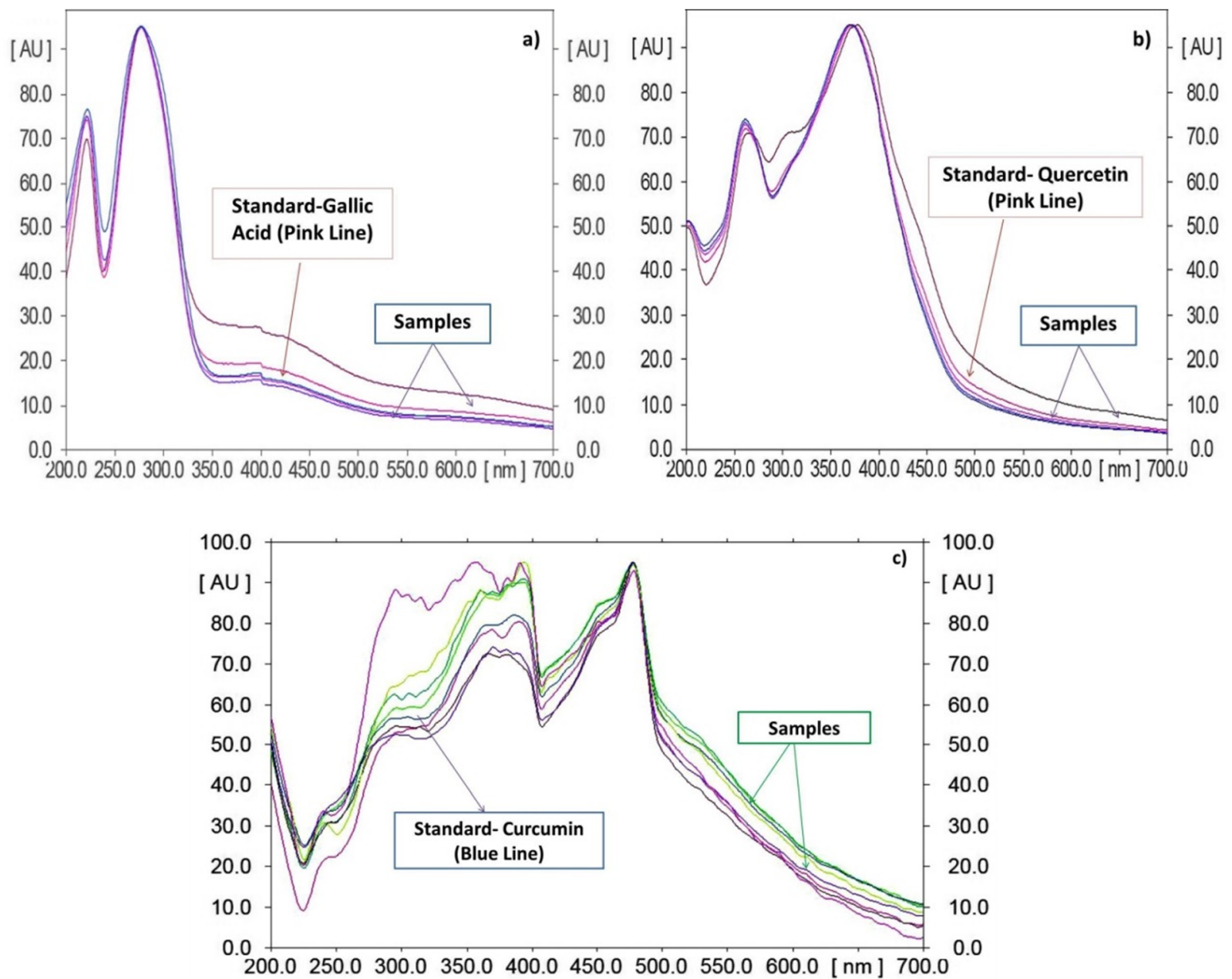

Fig. 4 Spectrum of gallic acid a), quercetin b) and curcumin c) at $366 \mathrm{~nm}$ superimposed with the formulation samples

(MC) formulation. The proposed method is simple, precise, specific, accurate, less time consuming and cost effective. Statistical analysis proved that the method is evitable for the analysis of xanthonoid, pentacyclic triterpenoids and phenolic compounds. The developed HPTLC method will help the manufacturer for standardization and routine quality control of raw materials and herbal products containing Swertia chirata and rhizome of Curcuma longa as an ingredient. Polyherbal formulations consist of multifarious mixture of phytoconstitutes wherein no single component is responsible for overall efficacy [9]. This causes a challenge in quality control standards for raw materials and standardization of herbal formulations [20]. Selecting one or more markers is a common practice in natural product analysis for purposes of identification and quality assessment [21].

In present study, three major bioactive compounds (mangiferin, oleanolic acid and ursolic acid) of S. chirata; one bio-marker compound (curcumin) of Curcuma longa and significant phenolic compounds viz. gallic acid and quercetin were present in significant amount in all the commercial test samples of MC. Analysis of bioactive compounds in the present study was performed using HPTLC methods and later HPTLC results were compared with HPLC. These two methods give comparable results and there was no statistically significant difference between the mean values for all extracts. Consequently, both HPTLC densitometry and the HPLC method could be used for the qualitative and quantitative estimation of these bio-active compounds in Mahasudarshan churna (MC) extracts. However, relatively HPTLC was found to be simple, fast and cost-effective method.

Our previous studies reported the presence of substantial amount of mangiferin and triterpenoids in Swertia chirata plant samples [12-14]. Kaur et al. [12, 13] quantified $3.87 \%$ ursolic acid, 3.27\% oleanolic acid and $4.31 \%$ 
Table 1 Method validation parameters for the quantification of Mangiferin, Oleanolic acid, Ursolic acid, Gallic acid, Curcumin and Quercetin

\begin{tabular}{|c|c|c|c|c|c|c|c|}
\hline Sr.no. & Parameters & Mangiferin (M) & $\begin{array}{l}\text { Ursolic acid } \\
\text { (UA) }\end{array}$ & $\begin{array}{l}\text { Oleanolic acid } \\
(\mathrm{OA})\end{array}$ & $\begin{array}{l}\text { Gallic } \\
\text { acid (GA) }\end{array}$ & Quercetin(Q) & Curcumin(C) \\
\hline 1 & $\begin{array}{l}\text { Linearity range (ng/spot; } \\
n=12^{\mathrm{a}}\end{array}$ & $200-800$ & $200-3000$ & $200-3000$ & $500-2000$ & $300-1500$ & $100-1000$ \\
\hline 2 & Correlation coefficient $\left(r^{2}\right)$ & 0.987 & 0.991 & 0.997 & 0.988 & 0.992 & 0.99 \\
\hline 3 & Regression equation & $Y=-608.4+9.033 X$ & $\begin{array}{l}Y=- \\
126.87 .0+ \\
11.05 X\end{array}$ & $\begin{array}{l}Y=- \\
1111.13+ \\
10.0914 X\end{array}$ & $\begin{array}{l}Y= \\
1939+ \\
7.19 X\end{array}$ & $\begin{array}{l}Y=-200+ \\
1.74 X\end{array}$ & $\begin{array}{l}Y=137+ \\
9.66 X\end{array}$ \\
\hline 4 & $\begin{array}{l}\text { Calculated SD value (CATS } \\
\text { software) }\end{array}$ & 6.72 & 2.59 & 3.26 & 5.33 & 2.12 & 2.43 \\
\hline 5 & $\begin{array}{l}\text { b }{ }^{\mathrm{Limit}} \text { of detection (LOD) } \\
(\mathrm{ng})[3 \times \mathrm{SD} / \mathrm{S}]\end{array}$ & 25 & 30 & 27 & 40 & 45 & 30 \\
\hline 6 & $\begin{array}{l}\text { bLimit of quantitation } \\
(\mathrm{LOQ})(\mathrm{ng})[10 \times \mathrm{SD} / \mathrm{S}]\end{array}$ & 75 & 90 & 81 & 125 & 140 & 90 \\
\hline 7 & $\mathrm{R}_{\mathrm{f}}$ & 0.53 & 0.38 & 0.59 & 0.28 & 0.48 & 0.56 \\
\hline 8 & $\lambda \max$ & $254 \mathrm{~nm}$ & \multicolumn{2}{|l|}{$520 \mathrm{~nm}$} & \multicolumn{3}{|l|}{$366 \mathrm{~nm}$} \\
\hline 9 & Mobile phase & $\begin{array}{l}\text { Ethyl acetate: glacial acetic acid: formic } \\
\text { acid: water (20: 2.2: } 2.2: 5.2 \mathrm{v} / \mathrm{v})\end{array}$ & \multicolumn{2}{|c|}{$\begin{array}{l}\text { n-hexane: ethyl acetate: } \\
\text { acetone (16.4: } 3.6: 0.2 \mathrm{v} / \mathrm{v})\end{array}$} & \multicolumn{3}{|c|}{$\begin{array}{l}\text { Toluene: ethyl acetate: formic acid } \\
(13.5: 9: 0.6 \mathrm{v} / \mathrm{v})\end{array}$} \\
\hline
\end{tabular}

${ }^{\mathrm{a}}$ Four concentration levels in triplicate; ${ }^{\mathrm{b}} \mathrm{SD}$ is the standard deviation of the blank response and $\mathrm{S}$ is the slope of the calibration plot

in aqueous ethanolic extracts of wild $S$. chirata collected from Western Himalayas, India. Pandey et al. [14] also reported $4.37 \%$ mangiferin yield in methanolic extracts of $S$. chirata wild samples collected from Eastern Himalayas, India. Moreover, wild sample of methanolic extract of Curcuma longa yielded 5.38\% content. S. chirata is considered as the most prolific source of important bioactive compounds [11]. Significant amount of ursolic acid, oleanolic acid and mangiferin compounds has been quantified in other Swertia species viz. S. angustifolia, S. alata, S. paniculata, S. minor, S. densifolia, S. lawii, S. corymbosa etc. $[22,23]$. S. chirata and other Swertia species have been widely used in the Ayurvedic, Unani and
Chinese herbal formulations for treating fever, malaria, epilepsy, ulcer, asthma, liver disorders, hepatitis, diabetes etc. as tinctures, infusions etc. [24].

Presence of significant marker compounds in MC formulations is in accordance with our previous reports of Swertia chirata herbs. Therefore these bio-marker compounds are authentic and can be efficiently used for the standardization of this polyherbal formulation.

\section{Conclusion}

A new HPTLC method has been developed and validated for the quantification of xanthonoid (mangiferin), triterpenoids (oleanolic acid and ursolic acid) and phenolics (gallic acid, quercetin and curcumin) in marketed

Table 2 Analytical characteristics of the method validation

\begin{tabular}{|c|c|c|c|c|c|c|c|}
\hline $\begin{array}{l}\text { Sr. } \\
\text { no. }\end{array}$ & Parameters & Mangiferin (M) & $\begin{array}{l}\text { Ursolic } \\
\text { acid (UA) }\end{array}$ & $\begin{array}{l}\text { Oleanolic } \\
\text { acid (OA) }\end{array}$ & $\begin{array}{l}\text { Gallic acid } \\
\text { (GA) }\end{array}$ & Quercetin (Q) & $\begin{array}{l}\text { Curcumin } \\
\text { (C) }\end{array}$ \\
\hline & Precision and accuracy & & & & & & \\
\hline 1 & Intra-day RSD (\%), $n=5$ & 0.437 & 0.357 & 0.487 & 0.67 & 0.56 & 0.45 \\
\hline \multirow[t]{2}{*}{2} & Inter-day RSD (\%),n= 5 (day-1/day-2/day-3) & $\begin{array}{l}0.437 / 0.495 / \\
0.512\end{array}$ & $\begin{array}{l}0.353 / \\
0.425 / 0.532\end{array}$ & $\begin{array}{l}0.484 / 0.498 / \\
0.514\end{array}$ & $\begin{array}{l}0.67 / 0.68 / \\
0.71\end{array}$ & $0.56 / 0.59 / 0.63$ & $\begin{array}{l}0.45 / 0.48 / \\
0.49\end{array}$ \\
\hline & Recovery & & & & & & \\
\hline 3 & $\begin{array}{l}\text { Amount of standard in } \mathrm{MC} \text { samples }\left(\mu \mathrm{g} \mathrm{mg}^{-1}\right) \\
\text { containing highest bioactive compounds }\end{array}$ & 44.6 & 8.1 & 19.2 & 20.1 & 10.3 & 6.1 \\
\hline 4 & Amount of standards added in $\mathrm{MC}$ sample $\left(\mu \mathrm{g} \mathrm{mg}^{-1}\right)$ & $20 / 40 / 60$ & $4 / 8 / 12$ & $10 / 20 / 30$ & $10 / 20 / 30$ & $5 / 10 / 15$ & $3 / 6 / 9$ \\
\hline 5 & Amount of standard found $\left(\mu \mathrm{g} \mathrm{mg}^{-1}\right)$ & $\begin{array}{l}64.36 / 84.4 / \\
104.26\end{array}$ & $\begin{array}{l}12.1 / 16.2 / \\
20.11\end{array}$ & $\begin{array}{l}29.21 / 39.19 / \\
49.12\end{array}$ & $\begin{array}{l}30.12 / 40.13 / \\
50.03\end{array}$ & $\begin{array}{l}15.29 / 20.28 / \\
25.33\end{array}$ & $\begin{array}{l}9.1 / 12.21 / \\
15.09\end{array}$ \\
\hline 6 & Recovery (\%) & $\begin{array}{l}99.62 / 99.76 / \\
99.67(99.81)\end{array}$ & $\begin{array}{l}100 / \\
100.62 / \\
100.04\end{array}$ & $\begin{array}{l}100.03 / \\
99.97 / 99.83\end{array}$ & $\begin{array}{l}100.06 / \\
100.07 / 99.86\end{array}$ & $\begin{array}{l}99.93 / 100.89 / \\
99.9 / 100.11\end{array}$ & $\begin{array}{l}100 / \\
100.9 / \\
99.93\end{array}$ \\
\hline
\end{tabular}


formulations of mahasudarshan churna containing Swertia chirata as a major ingredient. From the above mentioned results, it can be concluded that HPTLC technique is low cost, fast, precise, and accurate which can be successfully employed for the quantification of xanthonoid (mangiferin), triterpenoids (OA, UA) and phenolics (GA, quercetin and curcumin). Furthermore, the develop HPTLC method can be conveniently employed for routine quality control analysis of all the six marker compounds for marketed formulations in Ayurvedic/Herbal industry.

\section{Supplementary information}

Supplementary information accompanies this paper at https://doi.org/10. 1186/s12906-020-02970-z.

Additional file 1.

\section{Abbreviations}

MC: Mahasudarshan Churna; OA: Oleanolic acid; UA: Ursolic acid; GA: Gallic acid; C: Curcumin; Q: Quercetin; M: Mangiferin; HPTLC: High performance thin layer chromatography.

\section{Acknowledgements}

The authors are grateful to the IPLS-DBT Project (Project no. BT/PR-4548/INF/ 22/146/2012) sanctioned to Punjabi University, Patiala for providing the HPTLC facilities to carry out the present work.

\section{Authors'contributions}

PK did the experiment, TM help in writing the paper, AD helps in collection of plant samples, RCG helped in HPTLC analysis while DKP conceived the idea, did literature survey and supervised the work. All authors read and approved the final manuscript.

\section{Funding}

Lovely Professional University gave financial support but has no role in the study design, performance, data collection and analysis, decision to publish, or preparation/writing of the manuscript.

\section{Availability of data and materials}

The datasets used and/or analysed during the current study available from the corresponding author on reasonable request.

\section{Ethics approval and consent to participate}

Not applicable.

\section{Consent for publication}

Not applicable.

\section{Competing interests}

The authors declare that they have no competing interests. However, Dr. Abhiit Dey is the Associate Editor of this Journal.

\section{Author details}

${ }^{1}$ Department of Biotechnology, Lovely Faculty of Technology and Sciences, Lovely Professional University, Phagwara, Punjab 144411, India. ${ }^{2}$ Department of Botany, Punjabi University, Patiala, Punjab 147002, India. ${ }^{3}$ Department of Life Sciences, Presidency University, Kolkata, India. ${ }^{4}$ Department of Biochemistry, College of Medicine and Health Sciences, University of Gondar, Gondar, Ethiopia.
Received: 6 December 2019 Accepted: 24 May 2020

Published online: 11 June 2020

\section{References}

1. Verma S, Singh SP. Current and future status of herbal medicines. Veterinary World. 2008;1(11):347.

2. Huang Y, Wu Z, Su R, Ruan G, Du F, Li G. Current application of chemometrics in traditional Chinese herbal medicine research. J Chromatogr B. 2016;1026:27-35.

3. WHO. Guidelines for assessing quality of herbal medicines with reference to contaminants and residues. Geneva: World Health Organization; 2007.

4. Parasuraman S, Thing GS, Dhanaraj SA. Polyherbal formulation: concept of ayurveda. Pharmacogn Rev. 2014;8(16):73-80.

5. Garg S, Bhutani KK. Chromatographic analysis of Kutajarista - an ayurvedic polyherbal formulation. Phytochem Anal. 2008;19(4):323-8.

6. Shi X, Zhang K, Xue N, Su L, Ma G, Qi J, Wu Y, Wang Q, Shi Q. Differentiation of genuine Inula britannica $L$. and substitute specimens based on the determination of 15 components using LC-MS/MS and principal components analysis. Food Chem. 2013;141(4):4019-25.

7. Song S, Ma J, Tian Q, Tong L, Guo X. Hexachlorobenzene in human milk collected from Beijing, China. Chemosphere. 2013;91(2):145-9.

8. Tambekar DH, Dahikar SB. Antibacterial activity of some Indian Ayurvedic preparations against enteric bacterial pathogens. J Adv Pharm Tech Res. 2011;2(1):24

9. Rajopadhye AA, Namjoshi TP, Upadhye AS. Rapid validated HPTLC method for estimation of piperine and piperlongumine in root of Piper longum extract and its commercial formulation. Rev Bras. 2012;22(6):1355-61.

10. Chauhan S, Pundir V Sharma A. Pharmacopeial standardization of mahasudarshan churna: a polyherbal formulation. J Med Plants Stud. 2013; 1(2):13-8.

11. Kumar V, Van Staden J. A review of Swertia chirayita (Gentianaceae) as a traditional medicinal plant. Front Pharmacol. 2016;6:308.

12. Kaur P, Gupta RC, Dey A, Pandey DK. Simultaneous quantification of oleanolic acid, ursolic acid, betulinic acid and lupeol in different populations of five Swertia species by using HPTLC-densitometry: comparison of different extraction methods and solvent selection. Ind Crop Prod. 2019;130: $537-46$.

13. Kaur P, Pandey DK, Gupta RC, Dey A. Simultaneous microwave assisted extraction and HPTLC quantification of mangiferin, amarogentin, and swertiamarin in Swertia species from Western Himalayas. Ind Crop Prod. 2019:132:449-59.

14. Pandey DK, Basu S, Jha TB. Screening of different east Himalayan species and populations of Swertia L. based on exomorphology and mangiferin content. Asian Pac J Trop Biomed. 2012;2(3):S1450-6.

15. Pandey DK, Kaur P. Optimization of extraction parameters of pentacyclic triterpenoids from Swertia chirata stem using response surface methodology. 3. Biotech. 2018;8(3):152.

16. Pillai D, Pandita N. Validated high performance thin layer chromatography method for the quantification of bioactive marker compounds in Draksharishta, an ayurvedic polyherbal formulation. Rev Bras. 2016;26(5):558-63.

17. Sharma AS, Bhatt CJ, Pundarikakshudu K. High-performance thin-layer chromatographic method for the simultaneous quantification of piperine, piperlongumine, and 6-shogaol in Trikatu Churna-an Ayurvedic formulation. J Planar Chromatogr. 2017;30(1):43-9.

18. Shakeel S, Gul S, Zahoor A, Khan SS, Sheikh ZA, Naveed S, Usmanghani K. Standardization of biomarkers Gallic acid and Berberine in Polyherbal formulation Entoban capsules by high-performance thin-layer chromatography_densitometry. J Planar Chromatogr. 2015;28(5):386-90.

19. Bansal A, Chhabra V, Rawal RK, Sharma S. Chemometrics: a new scenario in herbal drug standardization. J Pharm Anal. 2014;4(4):223-33.

20. Rahman S, Haq FU, Ali A, Khan MN, Shah SM, Adhikhari A, El-Seedi HR, Musharraf SG. Combining untargeted and targeted metabolomics approaches for the standardization of polyherbal formulations through UPLC-MS/MS. Metabolomics. 2019;15(9):116.

21. Liu CX, Cheng YY, Guo DA, Zhang TJ, Li YZ, Hou WB, Huang LQ, Xu HY. A new concept on quality marker for quality assessment and process control of Chinese medicines. Chin Herb Med. 2017;9(1):3-13.

22. Kshirsagar PR, Pai SR, Nimbalkar MS, Gaikwad NB. Quantitative determination of three pentacyclic triterpenes from five Swertia L. species 
endemic to Western Ghats, India, using RP-HPLC analysis. Nat. Prod. Res. 2015;29:1783-8.

23. Gupta M, Bisht D, Khatoon S, Srivastava S, Rawat AKS. Determination of ursolic acid a biomarker in different Swertia species through high performance thin layer chromatography. Chin Med. 2011;2:121.

24. Li J, Zhao YL, Huang HY, Wang YZ. Phytochemistry and pharmacological activities of the genus Swertia (Gentianaceae), a review. Am J Chin Med. 2017;45:667-736

\section{Publisher's Note}

Springer Nature remains neutral with regard to jurisdictional claims in published maps and institutional affiliations.

Ready to submit your research? Choose BMC and benefit from:

- fast, convenient online submission

- thorough peer review by experienced researchers in your field

- rapid publication on acceptance

- support for research data, including large and complex data types

- gold Open Access which fosters wider collaboration and increased citations

- maximum visibility for your research: over $100 \mathrm{M}$ website views per year

At BMC, research is always in progress.

Learn more biomedcentral.com/submissions 